This is an Accepted Manuscript of an article published by Taylor \& Francis Group in Journal of Hunger \& Environmental Nutrition on 20 May 2014, available online: http://dx.doi.org/10.1080/19320248.2013.845868. A limited number of free eprints are available at:

http://www.tandfonline.com/eprint/aBny4THUxfhgpztDt8iA/full.

\title{
Food, place, and culture in urban Africa: comparative consumption in
}

\section{Gaborone and Blantyre}

\author{
Alexander F. Legwegoh (alegwego@gmail.com) ${ }^{a}$ \& Liam Riley (liam.john@gmail.com) ${ }^{\mathrm{b}}$ \\ ${ }^{a}$ Department of Geography, University of Guelph, Guelph, Ontario, Canada \\ ${ }^{\mathrm{b}}$ Department of Geography, Social Science Centre, The University of Western Ontario, \\ London, Ontario, Canada
}

\begin{abstract}
Urban food insecurity is an increasingly important research and policy challenge in urbanising sub-Saharan Africa. There is growing concern within food security literature about the paradoxical expansion of both hunger and obesity within African cities, and yet there is insufficient research from a social science perspective to explain the co-existence of dietary deficiency, micronutrient deficiencies, and obesity in Africa's diverse urban contexts. Locally appropriate strategies to address the multiple health effects of under- and over-nutrition are developed within unique environmental conditions and constraints, different economic systems, and different cultural milieux. These factors shape what foods are available, which ones are affordable, and how urban residents subjectively experience food security. This paper analyses the Household Dietary Diversity Scores (HDDS) from a regional survey, focusing on a qualitative comparison of Gaborone, Botswana and Blantyre, Malawi, to draw out the embedded differences in food consumption patterns in the two cities, raising several implications of these differences for understanding urban food security in sub-Saharan Africa. The comparison generates insights into the limitations of quantitative metrics of food security abstracted from the local context, and highlights the importance of geographical observations of environment, political economy, and culture for understanding urban food security.
\end{abstract}

Key Words: Urban, Food security, Dietary diversity, sub-Saharan Africa, Southern Africa, Gaborone, Blantyre 


\subsection{Urban food and nutritional security}

Health problems related to obesity and over nutrition are on the rise in southern Africa's urban communities, ${ }^{1}$ even as millions of the urban poor in the region cannot access adequate food on a consistent basis. Pinstrup-Anderson calls this intersection of health and hunger problems in Africa the "triple burden of malnutrition," wherein hunger (or dietary deficiency), micronutrient deficiencies and obesity (and related over-nutrition diseases) co-exist. ${ }^{2}$ The problem of urban food insecurity is more than the extent to which caloric requirements can be met; it also entails a detailed assessment of the nutritional quality, and hence the dietary diversity, of the kind of foods different households and individuals can access. ${ }^{3}$ Although the expansion of most African economies suggests rising prosperity, low-income urban households are finding it increasingly difficult to access or afford fresh and nutritious food. ${ }^{4,5}$ Conventional thinking in most policy circles focuses on increased consumption of fats, animal products, sugars and alcohol as people rely more on purchased food that is usually mass produced and highly processed. ${ }^{6,7}$ Dietary patterns in developing world cities are said to be in "transition," which implies a shift from ostensibly healthier "traditional" diets to potentially harmful "Western" diets. ${ }^{8}$ This model embeds several assumptions about the processes of development and urbanization that have been critically re-assessed by postcolonial geographers of African cities. These new perspectives emphasize the unique trajectories of urban development in different contexts, the non-linear temporality of urban development, the diverse forms of "modernity" in different contexts, and the continued socio-economic exclusion in ostensibly superior "developed" cities. $^{9,10}$

Dietary change is a key marker of the changes in urban environments, economies, and cultures. Changes in the quantity and quality of food eaten are potentially driven by multiple interacting factors, including: media and advertisement; time constraints; access to retail outlets and markets; and access to cooking, refrigeration and storage facilities. ${ }^{1}$ As Stupar et al. ${ }^{11}$ note in the case of South Africa, nutritional change is a complex process particularly because of 
differences in ethnicity and socio-economic factors, which need to be recognized in policy decisions. To identify and explain these factors, we draw upon the resurgence of comparative work within urban geography ${ }^{12-16}$ to critically reflect on the reasons for different food consumption patterns in Blantyre and Gaborone and the policy implications of these differences. The comparative analysis of two very distinct cities in southern Africa highlights several factors that shape the food security and nutritional status of low-income households in urban Africa. The stark contrast between Gaborone, where the food system is almost entirely integrated into South Africa's industrial food system, and Blantyre, where the vast majority of residents buy locally produced food from informal markets, throws into bold relief the diversity of urban food systems even within southern Africa, let alone the entire continent.

A cursive comparison of Blantyre and Gaborone clearly illustrates the limitations of the dietary transition theory. Gaborone ostensibly meets all the criteria for a "transitioned" city in that most diets are high in fat, protein, and processed foods and obesity is a growing public health concern. ${ }^{17}$ The problem with applying the transitional model is that "traditional" Tswana diets are mostly made up of beef and cereal grains, thus the heavily meat based diet in Gaborone is consistent with their "traditional" diet as well as a "Western" diet. The typical urban diet in Blantyre is perhaps closer to what dietary transition theorists would call a "traditional" diet in the sense that people customarily seek a balance of vegetables (especially green leafy vegetables), grains, and protein. The assumption that they will eventually transition overlooks the fact that people have lived there for over a century and that this $i s$ their urban diet. It is problematic to assume that with time, urban development will lead to the spread of generic forms of Western lifestyles and Western diets. ${ }^{10}$

Our comparison of food consumption patterns draws primarily from the African Food Security Urban Network (AFSUN) baseline survey, which found that food insecurity among low-income households was far more prevalent in Gaborone (82\%) than in Blantyre (51\%). ${ }^{18}$ This finding was counter-intuitive because by nearly any measure, Gaborone is more "developed" than Blantyre. For example, Botswana is considered an upper middle-income country with the poverty level of $12 \%$, whereas Malawi is a low income country with a poverty 
level of $67 \%$ (Table 1). In terms of household access to nutritious food, the AFSUN survey found that although in both Gaborone and Blantyre around 35-45\% of households have Household Dietary Diversity Scores (HDDS) of 5 or lower, diets in Gaborone tended to contain more potentially harmful or nutritionally neutral foods, such as oils, beverages, and "miscellaneous foods." ${ }^{19}$ On the other hand, less diverse diets in Blantyre more often included nutritionally valuable foods like vegetables and fish. We provide a comparative analysis of the quantitative findings from AFSUN and use this as a basis for explaining the differences in urban diets in Blantyre and Gaborone by drawing on qualitative case studies conducted simultaneously in each city. The qualitative data provides important information about what people are eating and why, thus contributing to a more detailed understanding of urban food insecurity in the two urban case studies.

Table 1: Socio-economic data on Botswana and Malawi

\begin{tabular}{|l|l|l|l|l|l|l|l|}
\hline & \multicolumn{3}{|l|}{ Population* (Thousand) } & GDP & Debt/GDP & Poverty \\
\cline { 2 - 6 } & Urban & Rural & Total & $\%$ Urban & per & ratio** & Ratio* \\
capita* & & \\
\hline Botswana & 1,252 & 779 & 2,031 & 62 & $\$ 8,680$ & 0.0 & $12 \%$ \\
\hline Malawi & 2,410 & 12,971 & 15,381 & 16 & $\$ 370$ & 26.3 & $67 \%$ \\
\hline
\end{tabular}

* World Urbanization Prospects: The 2011 Revision**Data from Southern African Development Community ${ }^{20}$

\subsection{Assessing urban household access to nutritious food in Gaborone \& Blantyre}

The comparative data in this paper are drawn from three sources: the AFSUN survey, the qualitative case study conducted in Gaborone on urban food consumption, and the qualitative case study conducted in Blantyre on gender and urban food security. The AFSUN survey was conducted by a multi-country team (not including the authors), and one of the authors conducted 
each of the qualitative case studies. Both of the authors visited the other city while conducting the qualitative case studies, such that comparative observations were drawn from direct experience as well as documented field data. The AFSUN survey targeted low-income neighbourhoods in eleven cities (Cape Town, Johannesburg, Msunduzi, Manzini, Maseru, Windhoek, Gaborone, Lusaka, Blantyre, Harare, and Maputo) and gathered information about 28,772 individuals in 6,452 households. ${ }^{21}$ The survey covered background characteristics of households and employed four measures of household food security status: Household Food Insecurity Access Scale (HFIAS), Household Food Insecurity Access Prevalence (HFIAP), Household Dietary Diversity Score (HDDS), and Months of Adequate Household Food Provisioning Indicator (MAHFP). In Gaborone, the AFSUN survey included 400 households with a total of 1,237 individuals. These households were randomly selected from three lowincome neighbourhoods: Old Naledi (150 households), Broadhurst (125 households), and White City/Bontleng (125 households). In Blantyre, 432 households including 2,730 individuals were surveyed within the low-income peri-urban neighbourhood of South Lunzu.

Findings from the HFIAS the HDDS portions of the survey were used for this paper. HFIAS is a continuous measure of the degree of food insecurity (in terms of access) in the household in the previous month. ${ }^{22}$ An HFIAS score is calculated for each household based on answers to nine "frequency-of-occurrence" questions covering people's anxiety about household food supply as well as insufficient quality (variety, preference) and supply. The scores range from 0 , which indicates that the household is food secure, to 27, which indicates that the household is severely food insecure. Given our focus on household dietary patterns, we are interested in the disaggregated HFIAS results for Gaborone and Blantyre, especially the response to the following three of the nine questions:

1. In the past four weeks were you or any household member not able to eat the kinds of foods you preferred because of a lack of resources?

2. In the past four weeks did you or any household member have to eat a limited variety of foods due to a lack of resources? 
3. In the past four weeks, did you or any household member have to eat some foods that you really did not want to eat because of a lack of resources to obtain other types of food?

Any inquiry on people's food preferences solicits responses based on their perceptions of the desirability and quality of the food. As such, Barrett notes that: "perceptions data may not suffice to capture utilization problems, such as those associated with micronutrient malnutrition" (page 827). ${ }^{23}$ To address this limitation, data from a more objective measure that captures the foods that households actually consumed provides us with an opportunity to broadly characterize the quality of people's diets.

In this regard, HDDS is a useful tool to capture local preferences and the quality of diets. It is based on a simple index of 12 food groups, with each group representing several different food items based on the local dietary context. For example, the food group "cereals" could include foods such as bread, rice, noodles, biscuits, millet, sorghum, or maize. ${ }^{24}$ The 12 food groups in the AFSUN survey were based on the 12-scale HDDS developed by the Food and Nutrition Technical Assistance (FANTA) Project of the United States Agency of International Development (USAID) ${ }^{24}$ and included:

(a) Cereals (foods made from grain);

(b) Roots or tubers;

(c) Vegetables;

(d) Fruits;

(e) Meat, poultry and offal;

(f) Eggs;

(g) Fish or shellfish;

(h) Foods made from beans, peas, lentils, or nuts;

(i) Cheese, yoghurt, milk, or other milk products;

(j) Foods made with oil, fat, or butter;

(k) Sugar or honey;

(1) Other foods. 
HDDS are values between 0 and 12, which represent the total number of food groups consumed by members of the household within a given reference period. The logic behind using food groups instead of individual foodstuffs is that by gauging the number of different food groups a household has consumed, it is possible to deduce that their diets offer a certain level of macroand micronutrient diversity. ${ }^{24}$ This makes the HDDS score more meaningful than an index that records the specific foods eaten, where a score of four might represent four foods of similar nutritional value (for example four cereals). ${ }^{24}$ HDDS has proven useful as a measure of food security within vulnerable populations because its data requirements are fairly easy to collect and analyze. ${ }^{25}$ HDDS has been validated in different countries as proxy measures of household per capita energy intake and a tool for monitoring household economic access to food, dietary patterns and the consumption of specific foods. ${ }^{26} \mathrm{We}$ argue that in order to expose the context specific causes of consumption patterns, it is useful to triangulate the scores with locally grounded information about the context in which people are making food consumption choices.

The qualitative case studies were designed after the AFSUN survey had been conducted with a view to producing data that could complement the quantitative survey findings and drill down into the qualitative factors that shape food consumption choices in each city. Although the quantitative measures utilized by AFSUN, especially the HDDS tool, integrates what Headey and Ecker term "nutritional relevance" into food security assessment, there is still limited research as to how to operationalize these measures across countries. ${ }^{27}$ For example, it is challenging to determine what numeric threshold can be used to determine adequate diets since the composition in terms of types of food groups is as important as the number of food groups. By explaining the context within which dietary patterns and scores occur, our qualitative studies help to inform a potential framework for comparing HDDS results in cities in different countries.

The qualitative case study in Gaborone was carried out in Broadhurst, one of the neighbourhoods involved in the AFSUN survey, which is home to $28.9 \%$ of the urban population. ${ }^{28}$ Broadhurst is very mixed in terms of hosting a wide range of people of diverse 
household structures and socio-economic status. Focusing on Broadhurst provided some geographical overlap with the survey data. By contrast, the qualitative case study in Blantyre set out to capture a broader view of the urban fabric and drew its participants from among six urban wards (Ndirande North, Likhubula, Soche East, Soche West, Limbe West and Nkolokoti). The spatial sampling strategy employed in Blantyre provided a wide range of formal and informal urban contexts. The qualitative fieldwork in Blantyre consisted of in-depth semi-structured household interviews $(\mathrm{N}=40)$, observation in markets, participative diagramming $(\mathrm{N}=43$ in eight groups), unstructured key informant interviews (individuals $\mathrm{N}=7$, groups $\mathrm{N}=46$ ), and newspaper analysis. The qualitative fieldwork in Gaborone consisted of in-depth semi-structured interviews $(\mathrm{N}=40)$ and observation of households, shopping malls and grocery shops. Each of the 40 households participating in interviews also kept 7-day food consumption diaries in which they noted the foods consumed during every meal.

\subsection{Results and analysis}

The AFSUN survey revealed widespread food insecurity across low-income urban neighbourhoods in southern Africa. It was found that of the households surveyed only $17 \%$ were food secure while the majority (57\%) were severely food insecure; $7 \%$ and $9 \%$, respectively, were mildly or moderately food insecure. ${ }^{5}$ The major drivers of inadequate access included income precarity, a narrowing of livelihood resources, and food price instability. ${ }^{5,21,29}$ The AFSUN results demonstrated that food insecurity in African cities is less strongly linked to aggregate food production and supply deficiency than to socio-economic inequality and the lack of planning for food access in low-income urban neighborhoods. The vast majority of urban residents purchase most of their food, which means that poorer households spend a disproportionately high amount of their income to access food and as a result, they often compromise on quality. The trade-off between cost and quality was reflected in the strong relationship between levels of food insecurity and household dietary diversity. ${ }^{1}$ Most households in the sample had inadequate dietary diversity and as levels of food security 
worsened, so too did dietary diversity scores. ${ }^{1}$ Furthermore, many households reported that they often did not eat their preferred diet, ate food that they did not like, and ate a diet that lacked diversity. ${ }^{1}$ Reliable statistics to illustrate the effects of poor diets in sub-Saharan Africa are in their infancy and urban statistics are unavailable, but World Health Organization data and emerging researches show growing rates of obesity. Prevalence rate of obesity for the region are estimated at about $7 \%$ amongst people age 20 and above. ${ }^{30,31}$ Obesity rates are even higher in some countries, particularly in the Southern African region where rates are as high as $33 \%$ in the Republic of South Africa, 23\% in Swaziland, 17\% in Lesotho and 11\% in Botswana. ${ }^{31}$ The rest of this section explores the details of the results for Blantyre and Gaborone, exposing as well as explaining similarities and differences.

\subsection{HFIAS: Perceptions of going without food}

The subjective assessment of food security is a popular method of assessment, particularly in resource-poor contexts where it is prohibitively expensive to catalogue every food consumed and calculate the adequacy of diets according to various nutritional metrics. ${ }^{27}$ The trade-off of the feasibility of subjective measurements of whether people feel that they are food secure is that the benchmark is a context-specific assessment by the surveyed population of what would be an adequate amount of food. On the one hand, this trade-off makes cross-case study comparison dubious without the aid of contextual information about the places being assessed. On the other hand, subjective assessments provide a realistic picture of whether food insecurity exists, in the sense of whether it is a phenomenon that is being experienced by the people who are surveyed. These trade-offs resonate with philosophical debates about the nature of poverty that are beyond the scope of this paper. ${ }^{32,33}$ While it is surprising that food security is higher in Blantyre than in Gaborone, it is less surprising considering that the main metric used was based on subjective reports of whether people perceived that they had access to food in adequate quantities and qualities. The more deeply impoverished population in Blantyre is likely to perceive as adequate a less diverse, yet sufficient, diet. The population in Gaborone, by contrast, is likely to have higher expectations that are not rooted in the lived experience of going hungry, 
as has happened in more recent memory in Malawi. ${ }^{34}$

Disaggregating the nine questions that comprise the HFIAS section of the survey, we find questions about people's perception of the insufficient quality of their food, including aspects of dietary diversity, nutritional adequacy, and preference. ${ }^{22}$ Table 2 outlines the results of the three HFIAS questions that capture people's perceptions of going without foods that they preferred, foods that lacked variety, and foods that they did not want. By all three measures, people in Gaborone were often unsatisfied with the quality of the foods. In Gaborone, many more households $(18.6 \%)$ were "often" not able to eat the kinds of foods they preferred than in Blantyre (5.6\%). Similarly, when asked about food variety, more households in Gaborone (16.8\%) were "often" unsatisfied with their food variety as compared to those in Blantyre (4.9\%). Finally, more households in Gaborone (20.8\%) reported having members who "often" consumed some foods that they really did not want to eat than in Blantyre (4.9\%). Furthermore, the proportion of respondents answering "no" to each of these questions, meaning that they had never had such an experience, was almost double in Blantyre compared to Gaborone in each case. Asked whether anyone in their household was not able to eat the kinds of foods they preferred because of a lack of resources, $41.9 \%$ in Blantyre and 22.4\% in Gaborone said "no." Asked whether anyone had to eat a limited diet because of a lack of resources, $44.2 \%$ in Blantyre and 21.5\% in Gaborone said "no." Thirdly, asked whether anyone had consumed food they did not want because of a lack of resources, $41.9 \%$ in Blantyre and 19.3\% in Gaborone said "no." These findings suggest that people in Blantyre were more likely to be satisfied with the types of food available to them, whereas to a greater extent households in Gaborone were dissatisfied, and hence experienced a higher degree of self-perceived food insecurity. It is important to note that in these questions, a single respondent answered for the entire household, possibly obfuscating intra-household maldistribution. ${ }^{35}$ Furthermore, the very distinctions between "no," "rarely," "sometimes," and "often" could have been understood differently in the different translations in each city. The meaning behind the data in Table 2 is inconclusive, but the HDDS results and the insights gathered through qualitative inquiry add vital insights into people's subjective perception of their consumption pattern in both cities. The combination of 
different types of information helps to address the inherent limitations of each single method for assessing the adequacy of access to nutritional food in Gaborone and Blantyre.

Table 2: Perceptions of the insufficient quality (AFSUN)

\begin{tabular}{|c|c|c|c|}
\hline & Gaborone & Blantyre \\
\hline & & $\%$ & $\%$ \\
\hline \multirow{4}{*}{$\begin{array}{l}\text { Were you or any household member not able } \\
\text { to eat the kinds of foods you preferred because } \\
\text { of a lack of resources? }\end{array}$} & No & 22.4 & 41.9 \\
\hline & Rarely & 36.4 & 23.6 \\
\hline & Sometimes & 22.6 & 28.9 \\
\hline & Often & 18.6 & 5.6 \\
\hline \multicolumn{2}{|l|}{ Total } & 100.0 & 100.0 \\
\hline \multirow{4}{*}{$\begin{array}{l}\text { Did you or any household member have to eat } \\
\text { a limited variety of foods due to a lack of } \\
\text { resources? }\end{array}$} & No & 21.5 & 44.2 \\
\hline & Rarely & 34.8 & 22.0 \\
\hline & Sometimes & 27.0 & 28.9 \\
\hline & Often & 16.8 & 4.9 \\
\hline \multicolumn{2}{|l|}{ Total } & 100.0 & 100.0 \\
\hline \multirow{4}{*}{$\begin{array}{l}\text { Did you or any household member have to eat } \\
\text { some foods that you really did not want to eat } \\
\text { because of a lack of resources to obtain other } \\
\text { types of food? }\end{array}$} & No & 19.3 & 41.9 \\
\hline & Rarely & 33.8 & 25.7 \\
\hline & Sometimes & 26.3 & 27.5 \\
\hline & Often & 20.8 & 4.9 \\
\hline \multicolumn{2}{|l|}{ Total } & 100.0 & 100.0 \\
\hline
\end{tabular}

\subsection{HDDS: what people are eating}

The HDDS findings provide a picture of what people are eating rather than their perceptions of the adequacy of the diets. The HDDS for each city is the average number of food categories eaten in the previous day. Table 3 shows the distribution of households by the percentage of households that consumed each number of food categories the previous day. Data are presented for Gaborone, Blantyre, and the entire AFSUN sample. While the scores from Gaborone range from 1 to 12 with a median score of 7 , those from Blantyre range from 0 to 11 with a median score of 6 . The total sample for all 11 cities ranged from 1 to 12 with a median score of $5 .^{21}$

A closer look at the results shows that while the HDDS in Gaborone ranged widely, many of households had scores of three or less (16\%), more than in Blantyre (9\%). As Figure 1 below shows, the HDDS in Blantyre populates between four and eight, with a stronger majority of households (79\%) in this range compared to Gaborone (56\%). More households in Gaborone (21.6\%) fall into the highly diverse category of 9- 
12 food categories than households in Blantyre (11.5\%). The greater likelihood that households will fall into the moderately diverse categories in Blantyre suggests a greater consistency in the range of foods households are able to access relative to Gaborone. This consistency contributes to a sense of being food secure relative to the norm, whereas the relative inconsistency of diversity scores among households in Gaborone suggests an enhanced sense of differentiation among households, which in turn creates a sense of lacking food access.

Table 3: Results in percentage of Household Dietary Diversity Score

\begin{tabular}{|r|l|r|r|r|}
\hline \multicolumn{2}{|l|}{} & \multicolumn{1}{|c|}{ Gaborone } & \multicolumn{1}{c|}{ Blantyre } & \multicolumn{1}{c|}{ Total } \\
\hline \multicolumn{2}{|c|}{ HDD Score } & \multicolumn{2}{|c|}{$\%$} & \multicolumn{1}{c|}{$\%$} \\
\hline & 1 & 5.1 & 0.5 & 2.3 \\
\hline & 2 & 5.1 & 3.3 & 11.0 \\
\hline & 3 & 5.7 & 5.5 & 10.1 \\
\hline & 4 & 7.0 & 12.9 & 11.3 \\
\hline & 5 & 9.5 & 17.1 & 13.5 \\
\hline & 6 & 11.1 & 20.5 & 13.0 \\
\hline & 7 & 20.0 & 16.4 & 11.9 \\
\hline & 8 & 14.9 & 12.1 & 10.4 \\
\hline & 9 & 9.7 & 6.0 & 7.2 \\
\hline & 10 & 4.3 & 5.0 & 4.0 \\
\hline & 11 & 2.7 & .5 & 2.2 \\
\hline & 12 & 4.9 & .0 & 2.5 \\
\hline
\end{tabular}

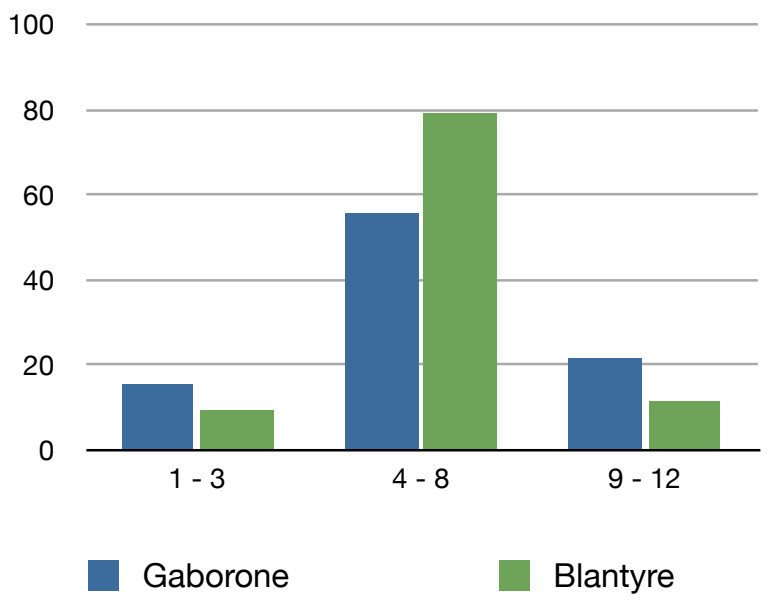

Figure 1: HDDS for Gaborone and Blantyre 
The data provided in Table 3 and Figure 1 reveal little about the food groups actually being consumed, most notably the extent to which the moderately diverse diets in Blantyre encompass a nutritionally adequate range of foods. Table 4 shows that households in Gaborone and Blantyre consumed foods from different categories. Table 4 ranks the 12 food groups based on the frequency of occurrence within household scores. "Cereals" (97.2\% in Gaborone and 99.1\% in Blantyre), "other foods" (including tea, coffee, and condiments) (75.8\% in Gaborone and $87.2 \%$ in Blantyre), and "sugar or honey" (73.5\% in Gaborone and $84 \%$ in Blantyre) were the three most frequently consumed food categories in both cities. In Gaborone, the fourth most frequent food group was "meat, poultry or offal," (66.5\%), followed by "vegetables" (64.7\%) and "foods made with oil, fat or butter" (63\%). In Blantyre, the fourth most frequent food group was "vegetables" (83.8\%), which were consumed almost as frequently as "other foods" and "sugar or honey," followed by "foods made with oil, fat, or butter" (53.5\%) and "fresh or dried fish or shellfish" (45.4\%). The following section of the paper explores the findings presented in Table 4 in-depth, focusing on the frequency, order of importance, and comparative characteristics of food categories in each city to understand the meanings behind the food consumption patterns and to outline the different types of food and nutrition insecurity in each city.

Table 4: Household Dietary Diversity Score: type of food eaten yesterday in order of frequency of occurrence (AFSUN)

\begin{tabular}{|l|l|l|l|}
\hline \multicolumn{2}{|c|}{ Gaborone } & \multicolumn{2}{c|}{ Blantyre } \\
\hline Food groups & $\%$ & Food Group & $\%$ \\
\hline 1. Cereals (foods made from grain) & 97.2 & 1. Cereals (foods made from grain) & 99.1 \\
\hline 2. Other foods & 75.8 & 2. Other foods & 87.2 \\
\hline 3. Sugar or honey & 73.5 & 3. Sugar or honey & 84.0 \\
\hline 4. Meat, poultry or offal & 66.5 & 4. Vegetables & 83.8 \\
\hline 5. Vegetables & 64.7 & 5. Foods made with oil, fat, or butter & 53.5 \\
\hline 6. Foods made with oil, fat, or butter & 63.0 & 6. Fresh or dried fish or shellfish & 45.4 \\
\hline 7. Roots or tubers & 57.0 & 7. Fruits & 42.9 \\
\hline $\begin{array}{l}\text { 8. Cheese, yoghurt, milk or other milk } \\
\text { products }\end{array}$ & 48.7 & $\begin{array}{l}\text { 8. Foods made from beans, peas, lentils, or } \\
\text { nuts }\end{array}$ & 30.9 \\
\hline 9. Fruits & 41.7 & 9. Meat, poultry or offal & 22.9 \\
\hline $\begin{array}{l}\text { 10. Foods made from beans, peas, lentils, } \\
\text { or nuts }\end{array}$ & 27.4 & 10. Roots or tubers & 22.5 \\
\hline $\begin{array}{l}\text { 11. Eggs } \\
\text { 12. Fresh or dried fish or shellfish }\end{array}$ & 23.6 & $\begin{array}{l}\text { 11. Cheese, yoghurt, milk or other milk } \\
\text { products }\end{array}$ & 17.9 \\
\hline & 12.8 & 12. Eggs & 15.6 \\
\hline
\end{tabular}




\subsection{Explaining urban diets with qualitative case studies}

This section explains local diets and preferences with outlines of some crosscutting factors that have shaped the consumption of foods in the HDDS categories in Blantyre and Gaborone. These factors help to explain multifaceted and multi-scalar relationships that exist between people's diets and their social and material environments in both cities, presenting trends for further scrutiny in other urban contexts. Using qualitative insights from both cities we will seek to explain that patterns going through all but one of the food categories in the HDDS tool. The category of "other foods," which was probably made up of condiments and beverages, was equal in both cities and difficult to assess because of the broad range of possible foods included.

\subsubsection{Starchy staples: "cereal" and "roots or tubers"}

Starchy staples are calorie rich but generally deficient in terms of proteins and micronutrients. For this discussion, we grouped together two food categories from the HDDS tool: "cereals" and "roots or tubers." In both cities, food made from grains stood out as the most popular food group consumed by $97 \%$ of households in Gaborone and $99 \%$ of households in Blantyre within the 24 hours prior to the survey. The high frequency of occurrence of cereals in dietary scores in both cities correlates with the makeup of the typical Batswana and Malawian diets. The typical lunch or dinner meal consists of a starchy staple (phaletshe in Botswana and nsima in Malawi) and a relish of meat, vegetables, or beans. The cereal of choice in both countries is maize, which was originally a New World crop, and yet it has become ubiquitous in southern African diets. ${ }^{36}$

In Botswana, white maize is the most popular and most affordable source of carbohydrate. The average domestic production is less than a tenth of national demand, which exceeds 100,000 MT per year. ${ }^{37}$ Although Botswana has a low population density and a vast amount of available land, poor soils and low rainfall (ranging from $250 \mathrm{~mm}$ per annum in the south west, to $400-550 \mathrm{~mm}$ in the east, to $650 \mathrm{~mm}$ in the north), make the land largely unreliable for farming. ${ }^{38}$ The annual shortfall is mostly met by imports from South Africa. There are some nutritional advantages to consuming South African maize, as milled maize is fortified based on South African legislation with vitamins including vitamin A, thiamin (vitamin B1), 
riboflavin (vitamin B2), niacin, folic acid, pyridoxine (vitamin B6) and minerals including iron and zinc. ${ }^{39}$ While the Government of Botswana encourages fortification of cereals and uses fortified sorghum in their feeding programs, Botswana has no laws that regulate cereal fortification. ${ }^{39}$ The qualitative study found that households did not only find maize meal affordable, they also found it easy to prepare in terms of skills required to cook as well as the time and energy required for preparation.

As with Botswana, maize has a central role in Malawian diets dating back centuries. ${ }^{40,41}$ The centrality of maize in people's diets was more emphatic in household interviews in Blantyre than Gaborone. Maize is so important in Malawi that many participants took questions about household food security as questions about access to maize. Follow-up questions were needed to learn about challenges in accessing other foods like vegetables and fish. The centrality of maize was illustrated in a statement by a middle-aged man in an informal settlement in Blantyre: "The first thing to buy is maize; maize needs to be always found in the home. Maize needs to be a priority because you can go and buy relish [the foods that accompany maize] but if there is no maize then things are not right." The social importance of maize for the subjective experience of being food secure is profoundly intertwined with the politics of food security in Malawi, where a vast majority of people are rural (Table 1), and most of these households rely on smallholder farming. The intensification of maize production in the past decade as a result of fertilizer subsidies and shrinking plot sizes has boosted yields and reduced hunger, but there are possible consequences over the longer term. ${ }^{42}$ Relative to other crops, overproduction of maize reduces the viability of soils and climate change presents a direct threat to this drought intolerant crop. ${ }^{43}$ The centrality of maize in Malawian food cultures, coupled with the Government's direct investment in fertilizer subsidies at the time of the AFSUN survey, go far in explaining why Blantyre appeared to be highly food secure in 2009 . In terms of roots and tubers, the data show a lower frequency of consumption of these foods in Blantyre despite the fact that FAO statistics highlight potatoes and cassava among the top national agricultural produces in $2011 .{ }^{44}$ Only $23 \%$ of households reported consuming roots or tubers in the last 24 hours, significantly fewer than the $99 \%$ who had consumed foods made 
of grains. The qualitative study suggests the main reason is that cassava and sweet potatoes tend to be eaten when maize gets too expensive or scarce, in the hungry season from November to February (the AFSUN survey was conducted in September). By contrast, in Gaborone roots and tubers are imported, and as such their availability does not correlate with national agricultural ecology or season. Rather, it depends on the ability of supermarkets to source the products from regional markets. The qualitative study revealed that while tubers (especially potatoes) are highly desired foods, especially fried, they are generally considered expensive. Nevertheless, $57 \%$ of the households surveyed had consumed roots or tubers in the last 24 hours, much of which would be potato fries readily purchased from grocery shops and fast food restaurants in the city. The qualitative study found that foods such as potato fries are often linked to the urban lifestyle of eating out and consuming convenience foods in Gaborone.

\subsection{2 "Fruits" and "vegetables"}

Vegetables are an important component of what is typically described as the common staple meal in both countries, which is the combination of a cereal with a vegetable side dish. Fruits and vegetables provide essential micronutrients (especially vitamin A) and are a vital part of a balanced diet. People in Blantyre were more likely to have consumed vegetables (84\%) than in Gaborone (65\%), while the rate of fruit consumption was similar in both cities (about 43\%). The high rate of consumption of vegetables is due in part to the rich horticultural environment in Blantyre, which makes it relatively easy to grow vegetables at home or in peri-urban farms. The severe water deficit in Gaborone makes growing vegetables more difficult and more costly in comparison. The municipal authorities have made concerted efforts to promote urban gardening at the household level and at large-scale commercial levels. ${ }^{45,46}$ Yet even with municipal leadership and investment, a key informant from Botswana's Ministry of Agriculture noted that there has been limited uptake at the household level. The commercial plots dedicated for horticulture in and around the city were under-utilized mainly because of the preference for non-agricultural economic activities and the arid environmental conditions. 
The high reliance on supermarkets in Gaborone means that people usually have the option of buying imported vegetables. The qualitative study in Gaborone revealed that people often buy small quantities of vegetables and consumed them immediately. This procurement pattern is especially clear within low-income households who often lack refrigerators. In contrast, the informal marketing system in Blantyre make locally produced vegetables more accessible; customers can bargain with vendors and purchase different vegetables in different quantities on a daily basis at informal markets close to their houses. The vibrant peri-urban markets surrounding Blantyre means that the informal vendor is often the only "middle man" between the producer and the customer, leading to lower food prices. In Gaborone, the lack of informal markets for low-income residents means that all residents pay a similar price for food. Low-income households are therefore more likely to reduce the amount of vegetables they purchase or buy cheaper processed foods in order to be able to afford meat and maize. Informal markets give low-income households in Blantyre more options for stretching their food budgets, such as: bargaining with vendors, requesting to purchase food on credit, or going to markets (perhaps less conveniently located) where the food is known to be less expensive.

\subsubsection{Animal proteins: "Meat, poultry or offal," "fresh or dried fish or shellfish" and "eggs"}

Foods derived from animals are not only important sources of protein and fat, but they also provide iron, calcium, and various micronutrients. Because of these benefits, and the cultural value associated with animal proteins, the increased consumption of animal products is often associated with rising prosperity. This is particularly true in cities where meat is available but not always affordable and the consumption of meat comes to signify affluence. In Botswana, there is increasing concern that the excessive consumption of fatty meat, combined with increasingly sedentary lifestyles, is raising the risk of non-communicable diseases such as heart disease. ${ }^{47,48}$ The HDDS results from the AFSUN survey captured the high consumption of foods in the "meat, poultry, or offal" category (66.5\%) and low consumption of "fresh or dried fish or shellfish" (12.8\%) in Gaborone. In Blantyre, "fresh or dried fish or shellfish" were far more 
commonly consumed (45.4\%) than "meat, poultry or offal" (22.9\%). Also, a higher proportion of households in Gaborone (23.6\%) had consumed eggs than in Blantyre (15.6\%) (Table 4).

The socio-cultural significance of beef in Botswana is similar to that of maize in Malawi. Meat, especially beef, is central to people's diets, livelihoods and the national economy. Beef or chicken serves as an accompaniment to cereal (maize), with the two making up the most frequently consumed meal within households in Gaborone. During the qualitative study it was common to witness people consuming maize meal with beef without vegetable relish for dinner, especially while socializing. Indeed, the combination of high consumption of maize meal, fatty meat and alcohol has become the central focus of public health experts concerned about the rising rate of obesity in Botswana. ${ }^{49}$ The importance of beef at urban dinner tables is a reflection of the symbolic importance of cattle within Botswana as this statement from a middle age male head of household highlights: "Cattle is every Motswana's pride, the number of cows you have shows how rich you are and cows are also important for funerals and weddings when we pay the lobola [bride price]." National agricultural policy and programs as well as private investment have therefore been biased towards beef production, making national arable farming largely under-productive.

In the city, chickens are competing with cattle in popularity, as poultry farming has now become a major policy focus of the municipal development plan. The sector has been praised for providing jobs, economic empowerment of urban entrepreneurs, and a healthier alternative to beef. ${ }^{50,51}$ Botswana has become self-sufficient in chicken production, which, coupled with its already well-established beef industry, explains the high availability and relative lower cost of beef and poultry in Botswana. The expansion of the commercial poultry farming in Gaborone also explains the relatively higher consumption of eggs in Gaborone over Blantyre.

Foods falling in the "meat, poultry, and offal" category are expensive foods in Blantyre relative to other sources of protein. They are more likely to be consumed on a weekly or occasional basis because of their high cost, such that a 24-hour time scale would underrepresent the number of households consuming meat on the weekend or on other special occasions. As one young man in a low-income household in a formal housing area noted: "meat 
is at the weekend when everyone is home because you can't eat meat during the week when someone is not around - then it is like taking him out of the family." In broad accordance with the dietary transition model, frequent meat consumption in Blantyre is associated with affluence and a higher-class status.

The physical environment of Botswana and Malawi, especially in terms of their inland waters (given that both countries are land-locked and have no marine fisheries) can be used to explain the difference in consumption of fish, which is much higher in Blantyre than in Gaborone. In Botswana, fish resources are limited and hardly of any economic value, with fish sources including the Okavango Delta, perennial rivers in the north western part of Botswana as well as dams that have been constructed to provide water for humans. Although fish and seafood imported from South Africa is readily available at supermarkets in Gaborone, most participants in the qualitative study expressed that they hardly consumed fish because they did not know how to prepare it. They related fish consumption to minority ethnic groups from the northeastern parts of Botswana and Zimbabwean migrants. In contrast, Lake Malawi provides a rich source of fish to Blantyre, mostly through informal trading networks. Dried fish is found in practically every informal food market in Blantyre, offering a range of qualities at a range of prices. Small fish with little flesh are affordable for most households, and prepared into a relish by frying or boiling them. The bones of the smaller fish are also consumed and they provide an important source of micronutrients for low-income consumers.

\subsubsection{Dairy products: "cheese, yoghurt, milk or other milk products"}

Dairy products are often recommended as good sources of high quality protein and micronutrients. They are especially important for infant nutrition. The data show a wide disparity between cities, with people in Gaborone far more likely to have consumed dairy products $(48 \%)$ than people in Blantyre $(18 \%)$. The data support the link made elsewhere ${ }^{52}$ between economic development and increased consumption of dairy products including cheese, condensed and evaporated milk and yoghurt. Gaborone's 
grocery shops are readily supplied with dairy products from South Africa. Imports include both fresh milk and shelf-staple milk, which could explain the higher than regional average (region average was $31 \%$ ) consumption of milk. The qualitative study showed that low-income households often lacked refrigeration, and as such the availability of shelf-stable milk on the market is a helpful alternative. A key informant from Botswana's Ministry of Agriculture noted that Botswana has yet to develop its dairy industry because most cattle are used for beef production. Malawi's dairy industry is underdeveloped relative to South Africa's, and as a result shelf-stable milk is less widely available and less affordable. Refrigerated milk is available at small shops, but most people associate milk with food for children. In addition to the relative accessibility of dairy products in Gaborone, it is worth noting that given Botswana's historic adherence to cattle, milk and milk products have been integrated into diverse dishes. For example, a common breakfast is made of sorghum porridge cooked with cultured milk (madila). Milk in Blantyre is mostly consumed by young children, and is rarely integrated into meals. Cheese and yoghurt are expensive and mostly found in supermarkets catering to high income households.

\subsubsection{Vegetable proteins: "foods made from beans, peas, lentils or nuts"}

Foods made from beans, peas, lentils or nuts provide important proteins and amino acids. In both cities, the consumption of these foods was not as high as the trends we have explored for the other food groups. The consumption of foods in this category was slightly lower in Gaborone (27\%), than in Blantyre (31\%). One might assume that these sources of protein would be more popular because they are inexpensive relative to animal proteins, but they also cost more to process in terms of fuel and time. In Gaborone, people noted in interviews that while they enjoy traditional dishes including dikgobe [cracked maize and bean] and morogo wa dinawa ka dobi [bean-leaf vegetable with groundnuts], they tend not to consume these in the 
city, citing the energy and time expense of preparing them. People contrasted their busy lives in the city as well as the fact that in the city propane or electricity typically used for cooking tend to be expensive. They factor all of these considerations - not only the cost of the food itself into the choice of household meals, noting that in the rural areas people can use fuel wood to cook these dishes and can afford the length of time essential to prepare these meals. Similar considerations seem to be at play in Blantyre, where $79 \%$ of households use charcoal or firewood for cooking. ${ }^{53}$ When discussing the time it takes to cook a meal, one man in a lowincome household in an informal neighbourhood said: "beans can take some time but if it is eggs, matemba [dried fish] you just fry in oil, or if there is no oil you just roast on charcoal." The time constraints for cooking in the city reflect the multiple roles that women play within their households, often earning money for the household as well as providing care and preparing food.

\subsubsection{High calorie foods: "foods made with oil, fat or butter" and "sugar or honey"}

Animal fats, vegetable oils, and sugar are useful in making food more palatable and are important sources of dietary energy thus in moderate quantities they are an essential part of a healthy diet. ${ }^{54}$ However, the adverse effects of animal fats, vegetable oils, and sugar on human health has been a major focus within nutrition security literature, especially in terms of the rising rates of obesity in cities of the Global South. ${ }^{55,56}$ High levels of urbanization and economic growth have been correlated with the high consumption of these calorie dense foods, which are more likely to be purchased already processed and therefore less time consuming to prepare. The heightened consumption of "foods made with oil, fat, or butter" in Gaborone (63\%) relative to Blantyre (54\%) is consistent with the link to economic prosperity. This correlation ignores "traditional" uses of oil that are not part of a highly processed diet. The finding that almost half of the households surveyed in Blantyre did not consume oil the day before the survey more likely means they could not afford it than that they made a "healthy choice" to prepare their food without fat or oil. The preferred method of cooking vegetables requires oil, yet the data show that $30 \%$ of the households that consumed vegetables did not 
consume oil, suggesting that they prepared the vegetables in a less preferred form by simply boiling them. The findings for Gaborone, by contrast, fit the narrative of urban dietary transition in that fried foods are widely available and often more affordable than fresh foods. People noted the popularity of convenience foods, such as fat cakes, which are often deep-fried rather than cooked.

Sugar consumption plays a similar role to fried foods in the dietary transition narrative. The HDDS data shows that more people in Blantyre (84\%) had consumed "sugar or honey" than those in Gaborone (74\%). The qualitative study in Blantyre suggested that sugar consumption in Malawi is partly a response to caloric deficiency in that some people consumed sugar, which is cheap, to avoid feel hungry. In both cities, we noted people's strong affinity to consume tea or coffee for breakfast and this drives up the consumption of sugar in both cities. The typical breakfast in Blantyre would include very sweet tea. In Gaborone, many people consume soft maize porridge sweetened with sugar for breakfast. The reasons behind the consumption of these ostensibly problematic categories, at least from the perspective of the growing obesity epidemic, show a nuanced picture of how people make food choices. The time convenience that leads households in Gaborone to buy ready-made fried food and households in Blantyre to fry their vegetables in oil rather than boiling beans reflects an economic issue of the time pressure of urban labor, particularly women's labor. Also perhaps counter-intuitively, the more widespread consumption of sugar in Blantyre could be masking higher levels of food insecurity in terms of caloric deficiency related to the economic inaccessibility of more nutritious foods. ${ }^{57}$

\subsection{Environment, political economy, and culture shape food consumption patterns}

The AFSUN findings allow us to draw in all of these different types of observations about the complexity of urban food security, especially in terms of the types and quality of foods people have access to in Gaborone and Blantyre. HFIAS exposes people's perception of and level of satisfaction with their food quality, HDDS shows the levels of dietary diversity and the food groups people often access, while the qualitative insights help explain why and how households come to lack access to certain food groups. From the above analysis, we can draw attention to 
the crosscutting themes of environment, political economy, and culture in shaping food consumption differently in different cities. First, the physical environment is quite distinct between Blantyre and Gaborone. Blantyre's environment is highly productive for agriculture, with favourable soils and rainfall patterns. Gaborone, by contrast, is located in a semi-arid climate with relatively poor soils. The prominence of horticulture and crop production (especially maize) in Blantyre contrasts with the livestock production and heavy dependence on South Africa for fresh produce in Gaborone.

Second, the political economy of both countries is very different, with Gaborone being a middle-income city, largely planned and built to serve a middle-income population with electricity, public transit, and supermarkets. Blantyre, on the other hand, is in a very low-income country and has had very weak local governance for most of its history. Most public goods, particularly in low-income informal settlements, are provided through non-state actors such as traditional authorities, religious communities, and charitable organizations. ${ }^{58}$ The predominance of the informal food economy yields benefits and drawbacks as noted above. Botswana's state institutions have been buttressed by the lucrative diamond sector, through which it receives funds that are then directed to ensuring food security through imports from South Africa. Import subsidies on grain contribute to the fact that the maize remains the carbohydrate of choice, while government and private investment in livestock production contributes to the high consumption of animal proteins. The government of Botswana also invest substantial amounts of mineral revenue into HIV/AIDS prevention and care, which significantly impacts the country given the prevalence rate amongst 15-49 years old antenatal women in the public health clinics of $31.8 \%$ in $2009 . .^{59,60}$ This could potentially impact the government's ability to maintain an import based food security model while the disease could significantly reduce the countries adult workforce. At the same time good nutrition and divers diets are recommended as essential complement to antiretroviral drugs to improve the weakened immune system of those living with HIV/AIDS. ${ }^{59,60}$ Hence it is important for Botswana to combine measures that improve access to health diets within HIV/AIDS programs. In Malawi, the state has invested heavily in 
boosting maize production through fertilizer subsidies even as other agricultural products have declined and it has reduced subsidies for food marketing.

Third, the food cultures, which have evolved in both cities within their respective national cultures, also portray distinct characteristics because of people's diverse circumstances in the city. For example, the popular consumption of nutritious food categories like vegetables and fish in Blantyre is partly motivated by the cultural norm of eating these foods with the starchy staple. The low consumption of fish in Gaborone was not the result of fish being unavailable or unaffordable, but rather that people were not used to eating fish and associated it with inferior cultural groups. The unhealthy frequent consumption of beef in Gaborone is also cultural. The municipal government's attempts to improve public health by supporting vegetable production in urban gardens have been thwarted by these biases and preferences, which can be slow to change. Food cultures determine what is interpreted as food security, and the qualitative studies showed that beef is central to most Motswana's sense of food security in the same way that maize is central to most Malawians' sense of food security. These cultural attitudes are important to understand before making nutritional interventions to address the triple-burden of hunger, over- and under-nutrition.

\subsection{Conclusion}

The contrasting physical environments, political economies, and cultural meanings associated with food in Gaborone and Blantyre underpin food consumption patterns in each city and shape the food security findings from the AFSUN survey. As a result of our integration of these themes in our analysis, broadly based explanations as to why people in both cities eat the way they do emerged. Drawing on multiple themes allowed us to paint a more grounded picture of comparative urban food consumption that goes beyond the abstract idea of "dietary transition" which is rooted in a problematic conceptual duality of "traditional" and "modern" forms of food consumption. The study provides an opportunity for policymakers in Gaborone and Blantyre to address the concern around the nutritional quality of the foods people were consuming by 
developing supply-side assessments of the accessibility of diverse diets and demand-side assessments of why people choose certain foods. ${ }^{61}$

Direct policy action in the case of Gaborone could be to increase the accessibility of fruits and vegetables through investment in alternative marketing channels and local food production. This would be most effective coupled with a public awareness campaign to boost the desirability of fruits and vegetables. A public awareness campaign in Blantyre would also help to address the nutritional disadvantages of a diet overly focused on maize consumption. Decoupling maize from food security would allow for a diversification of staple food consumption, while highlighting the nutritional advantages of legumes, fish and vegetables could buttress the inherent strengths of the local diet. Our analytical combination of quantitative and qualitative methods helped to unlock hitherto under-explored linkages between environment, culture, and political economy that drive urban food consumption patterns, including the contradictory patterns that lead to simultaneous over-nutrition and hunger.

\section{Reference}

1. Crush J, Frayne B, McLachlan M. Rapid Urbanization and the Nutrition Transition in Southern Africa. Vol No. 7: African Food Security Urban Network (AFSUN); 2011.

2. Pinstrup-Andersen P. The African Food System and Human Health and Nutrition: a conceptual and empirical overview. In: Pinstrup-Andersen P, ed. The African Food System and Its Interaction with Human Health and Nutrition, Cornell University Press, Ithaca: Cornell University Press; 2010:1-13.

3. Pinstrup-Andersen P. Special Debate Section Can Agriculture Meet Future Nutrition Challenges? European Journal of Development Research. 2013;25(1):5-12.

4. Battersby J. Beyond the food desert: finding ways to speak about urban food security in South Africa. Geografiska Annaler: Series B, Human Geography. 2012;94(2):141-159.

5. Crush J, Frayne B, Pendleton W. The Crisis of Food Insecurity in African Cities. Journal of Hunger \& Environmental Nutrition. 2012;7(2-3):271-292.

6. Atkinson SJ. Approaches and actors in urban food security in developing countries. Habitat International. 1995;19(2):151-163.

7. Roetter RP, Van Keulen H. Food security. Science for agriculture and rural development in low-income countries. Springer, Dordrecht. 2007:27-56.

8. Popkin BM, Doak CM. The obesity epidemic is a worldwide phenomenon. Nutrition reviews. 2009;56(4):106-114.

9. Edensor TJ, Jayne M. Urban theory beyond the West: a world of cities. Routledge; 2011. 
10. Parnell S, Robinson J. (Re) theorizing Cities from the Global South: Looking Beyond Neoliberalism. Urban Geography. 2012;33(4):593-617.

11. Stupar D, Eide WB, Bourne L, Hendricks M, Iversen PO, Wandel M. The nutrition transition and the human right to adequate food for adolescents in the Cape Town metropolitan area: Implications for nutrition policy. Food Policy. 2012;37(3):199-206.

12. Gough KV. Reflections on conducting urban comparison. Urban Geography. 2012;33(6):866-878.

13. McFarlane $\mathrm{C}$, Robinson J. Introduction-Experiments in Comparative Urbanism. Urban Geography. 2012;33(6):765-773.

14. Robinson J. Comparisons: colonial or cosmopolitan? Singapore Journal of Tropical Geography. 2011;32(2):125-140.

15. Robinson J. Cities in a world of cities: the comparative gesture. International Journal of Urban and Regional Research. 2011;35(1):1-23.

16. Ward K. Towards a relational comparative approach to the study of cities. Progress in human geography. 2010;34(4):471-487.

17. World Health Organization. Botswana-NCD Country Profile, 2011. 2011.

18. Frayne $\mathrm{B}$, Pendleton $\mathrm{W}$, Crush $\mathrm{J}$, et al. The state of urban food insecurity in southern Africa. AFSUN Cape Town; 2010.

19. AFSUN. AFSUN Policy Brief Gaborone. African Food Security Urban Network;2009.

20. World Urbanization Prospects: The 2011 Revision. United Nations; 2012. http://esa.un.org/unup/.

21. Frayne B, Pendleton W, Crush J, et al. The State of Urban Food Insecurity in Southern Africa. Vol No. 2: African Food Security Urban Network (AFSUN); 2010.

22. Coates J, Swindale A, Bilinsky P. Household Food Insecurity Access Scale (HFIAS) for Measurement of Food Access: Indicator Guide (v.3). Washington, D.C.: Food and Nutrition Technical Assistance Project, Academy for Educational Development,;2007.

23. Barrett C. Measuring food insecurity. Science. 2010;327(5967):825.

24. Swindale A, Bilinsky P. Household Dietary Diversity Score (HDDS) for measurement of household food access: Indicator guide. Food and Nutrition Technical Assistance Project, Washington. 2006.

25. Thorne-Lyman AL, Valpiani N, Sun K, et al. Household dietary diversity and food expenditures are closely linked in rural Bangladesh, increasing the risk of malnutrition due to the financial crisis. Journal of Nutrition. 2010;140(1):182S.

26. Kennedy G, Berardo A, Papavero C, et al. Proxy measures of household food consumption for food security assessment and surveillance: comparison of the household dietary diversity and food consumption scores. Public Health Nutrition. 2010;13(12).

27. Headey D, Ecker O. Rethinking the measurement of food security: from first principles to best practice. Food Security. 2013:1-17.

28. Central Statistics Office. Demographic Indicators. In: Office CS, ed. Gaborone: Central Statistics Office; 2011.

29. Crush JS, Frayne GB. Urban food insecurity and the new international food security agenda. Development Southern Africa. 2011;28(4):527-544.

30. Ziraba A, Fotso J, Ochako R. Overweight and obesity in urban Africa: A problem of the rich or the poor? BMC Public Health. 2009;9(1):465. 
31. Overweight / Obesity: Obesity (body mass index $\geq 30$ ) by WHO region. 2013. http://apps.who.int/gho/data/view.main.2480?lang=en. Accessed 22/05/2013.

32. Agarwal B, Humphries J, Robeyns I, eds. Amartya Sen's Work and Ideas: A Gender Perspective. Taylor \& Francis; 2005.

33. Rahnema M. Poverty. In: Sachs W, ed. The development dictionary: A guide to knowledge as power: Zed Books; 2010.

34. Devereux S, Tiba Z. Malawi's first famine, 2001-2002. In: Devereu S, ed. The new famines: why famines persist in an era of globalization: Routledge; 2006:143 - 177.

35. Dodson B, Chiweza A, Riley L. Gender and food insecurity in southern African cities. African Food Security Urban Network (AFSUN); 2012.

36. McCann J. Maize and grace: Africa's encounter with a New World crop, 15002000. Harvard University Press; 2009.

37. Botswana Agricultural Marketing Board. Agricultural Products: Maize. 2013; http://www.bamb.co.bw/site/index.php/maize. Accessed 03/07/2013, 2013.

38. Zhou PP, Simbini T, Romokgotlwane G. Southern African Agriculture and Climate Change: A Comprehensive Analysis-Botswana. International Food Policy Research Institute (IFPRI);2013.

39. Seleka TB, Jackson JC, Batsetswe L, Kebakile PG. Small-scale milling and the feasibility of mandatory fortification of sorghum and maize flour in Botswana. Development Southern Africa. 2011;28(4):461-476.

40. Mandala EC. The end of Chidyerano: a history of food and everyday life in Malawi, 1860-2004. Praeger Publishers; 2005.

41. Smale M. "Maize is life": Malawi's delayed Green Revolution. World Development. 1995;23(5):819-831.

42. Dorward A, Chirwa E. The Malawi agricultural input subsidy programme: $2005 / 06$ to 2008/09. International journal of agricultural sustainability. 2011;9(1):232-247.

43. Snapp SS, Blackie MJ, Gilbert RA, Bezner-Kerr R, Kanyama-Phiri GY. Biodiversity can support a greener revolution in Africa. Proceedings of the National Academy of Sciences. 2010;107(48):20840-20845.

44. FAO CountrySTAT. FAO; 2013. http://www.fao.org/economic/ess/esscapacity/countrystathome/en/. Accessed 22/05/2013.

45. Keboneilwe D, Madisa M. Policy development and implementation by MOA Botswana. Paper presented at: Workshop on urban micro-farming and HIVAIDS, Johannesburg/Cape Town, South Africa2005.

46. Madisa M, Assefa Y. Impact of government financial incentives on peri-urban vegetable production in Botswana. Journal of Horticulture and Forestry. 2011;3(8):264-269.

47. Letamo G. The prevalence of, and factors associated with, overweight and obesity in Botswana. Journal of biosocial science. 2011;43(01):75-84.

48. Wrotniak B, Malete L, Maruapula S, et al. Association between socioeconomic status indicators and obesity in adolescent students in Botswana, an African country in rapid nutrition transition. Pediatric Obesity. 2012;7(2):e9-e13.

49. Clausen $\mathrm{T}$, Charlton K, Holmboe-Ottesen G. Nutritional status, tobacco use and alcohol consumption of older persons in Botswana. The journal of nutrition, health \& aging. 2006;10(2):104-110.

50. Hovorka A. Transspecies urban theory: chickens in an African city. cultural geographies. 2008;15(1):95-117. 
51. Hovorka AJ. Entrepreneurial opportunities in Botswana:(re) shaping urban agriculture discourse. Journal of contemporary African studies. 2004;22(3):367388.

52. Smith J, Sones K, Grace D, MacMillan S, Tarawali S, Herrero M. Beyond milk, meat, and eggs: Role of livestock in food and nutrition security. Animal Frontiers. 2013;3(1):6-13.

53. Malawi National Statistics Office. Integrated household survey 2010-2011. In: MNSO, ed. Zomba2012.

54. Drewnowski A, Popkin BM. The nutrition transition: new trends in the global diet. Nutrition reviews. 1997;55(2):31-43.

55. Popkin BM. The nutrition transition is speeding up: a global perspective. In: Temple NJ, Wilson T, Jacobs DR, Jr, eds. Nutritional Health: Strategies for Disease Prevention. New York: Humana Press; 2012:85-99.

56. Popkin BM, Adair LS, Ng SW. Global nutrition transition and the pandemic of obesity in developing countries. Nutrition reviews. 2012;70(1):3-21.

57. Temple NJ, Steyn NP. The cost of a healthy diet: A South African perspective. Nutrition. 2011;27(5):505-508.

58. Cammack D. Local governance and public goods in Malawi. IDS bulletin. 2011;42(2):43-52.

59. Reid M, Mosepele M, Tsima B, Gross R. Addressing the challenge of the emerging NCD epidemic: lessons learned from Botswana's response to the HIV epidemic [Unresolved issues]. Public Health Action. 2012;2(3):47-49.

60. The department of HIV and AIDS Prevention \& Care (DHAPC) Botswana. Botswana HIV/AIDS Programmes. 2013; http://www.hiv.gov.bw/content/aboutus. Accessed 06/09/2013, 2013.

61. Herforth A. Nutrition and the environment: fundamental to food security in Africa. In: Pinstrup-Andersen P, ed. The African Food System and Its Interaction with Human Health and Nutrition. Ithaca, NY: Cornell University Press in cooperation with the United Nations University: Cornell University Press; 2010:128-160. 